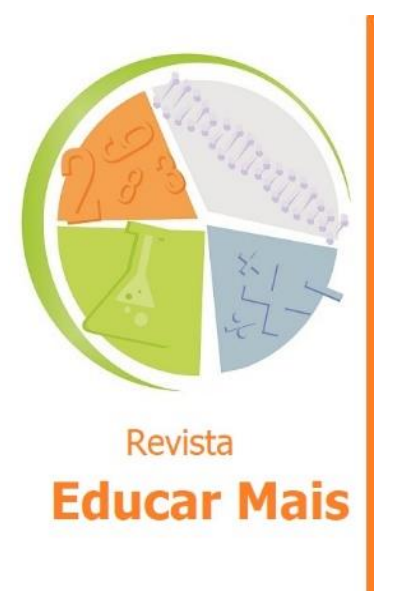

\title{
Currículo, cultura e conhecimento: concepções e inferências
}

\section{Curriculum, culture and knowledge: conceptions and inferences}

Currículo, cultura y conocimiento: concepciones e inferencias

Rejane Aguiar Alcântara Neves ${ }^{1}$; Natal Lânia Roque Fernandes $^{2}$;

Patricia Ribeiro Feitosa Lima ${ }^{3}$ (D)

\section{RESUMO}

O objetivo deste artigo é refletir sobre as relações entre currículo, cultura e conhecimento, a fim de compreender os lugares que ocupam no campo dos estudos curriculares e nas discussões de teóricos que se debruçam sobre as implicações dessa relação para o fazer pedagógico. As teorias elaboradas sobre currículo têm discutido o currículo, a cultura e o conhecimento de acordo com o contexto histórico e de diferentes perspectivas. Os estudos culturais possibilitaram às teorizações curriculares uma concepção de conhecimento e de currículo como campos culturais sensíveis às relações de poder. Consideramos que não há possibilidades do currículo escolar existir sem influências dos processos culturais presentes nos contextos em que ele é vivenciado. $\mathrm{Na}$ prática, a relação conhecimento e cultura perpassa por todas as linearidades que o currículo possa apresentar, como por exemplo: base comum, parte diversificada e a prática cotidiana em sala de aula.

Palavras-chave: Conhecimento; Currículo; Cultura; Ensino.

\begin{abstract}
The objective of this article is to reflect on the relationships between curriculum, culture and knowledge, in order to understand the places they occupy in the field of curriculum studies and in the discussions of theorists who focus on the implications of this relationship for pedagogical practice. The theories developed about curriculum have discussed the curriculum, culture and knowledge according to the historical context and from different perspectives. Cultural studies enabled curriculum theorizations to conceive of knowledge and curriculum as cultural fields sensitive to power relations. We consider that there is no possibility for the school curriculum to exist without the influences of the cultural processes present in the contexts in which it is experienced. In practice, the relationship between knowledge and culture permeates all the linearities that the curriculum may present, such as: common base, diversified part and everyday practice in the classroom.
\end{abstract}

Keywords: Knowledge; Curriculum; Culture; Teaching.

\footnotetext{
${ }^{1}$ Licenciada em Pedagogia e cursando Mestrado Profissional em Educação Profissional e Tecnológica (ProfEPT) no Instituto Federal de Educação, Ciência e Tecnológica do Ceará (IFCE), Fortaleza/CE - Brasil. E-mail: rejaneaguiaralcantara@gmail.com

${ }^{2}$ Doutora em Educação e Docente do Curso de Mestrado Profissional em Educação Profissional e Tecnológica (ProfEPT) do Instituto Federal de Educação, Ciência e Tecnologia do Ceará (IFCE), Fortaleza/CE - Brasil. Email: laninharoque@gmail.com

${ }^{3}$ Doutora em Educação e Docente do Mestrado Profissional em Educação Profissional e Tecnológica (ProfEPT) do Instituto Federal de Educação, Ciência e Tecnologia do Ceará (IFCE), Fortaleza/CE - Brasil. E-mail: patriciafeitosa@ifce.edu.br
} 


\section{RESUMEN}

El objetivo de este artículo es reflexionar sobre las relaciones entre currículo, cultura y saber, para comprender los lugares que ocupan en el campo de los estudios curriculares y en las discusiones de teóricos que se centran en las implicaciones de esa relación para la práctica pedagógica. Las teorías desarrolladas sobre el currículo han discutido el currículo, la cultura y el conocimiento según el contexto histórico y desde diferentes perspectivas. Los estudios culturales permitieron que las teorizaciones curriculares concibieran el conocimiento y el currículo como campos culturales sensibles a las relaciones de poder. Consideramos que no hay posibilidad de que el currículo escolar exista sin las influencias de los procesos culturales presentes en los contextos en los que se vive. En la práctica, la relación entre saber y cultura permea todas las linealidades que el currículo pueda presentar, tales como: base común, parte diversificada y práctica cotidiana en el aula.

Palabras clave: Conocimiento; Currículo; Cultura; Enseñanza.

\section{INTRODUÇÃO}

As rápidas transformações sociais e econômicas, impulsionadas pelo desenvolvimento de novas tecnologias, têm possibilitado o acesso a informações e conhecimentos diversificados. No entanto, observa-se que nas camadas das classes sociais menos favorecidas economicamente, o acesso ao conhecimento é cada vez mais desafiante. Crianças e jovens das camadas pobres enfrentam dificuldades de aprendizagem, estando sujeitas à evasão escolar. O Índice de Desenvolvimento da Educação Básica (Ideb) de 2019 revelou que apenas 35,9\% dos alunos do 90 ano, da rede pública de ensino, tinham nível de aprendizagem adequado em Português e 18,4\% em Matemática (FARIA, 2020). Uma realidade aquém da esperada na cultura de uma sociedade letrada e desenvolvida tecnologicamente.

A realidade contraditória exposta nos instiga a refletir sobre os desafios demandados à escola, especificamente ao currículo no qual se assenta o processo educativo escolar. Um dos desafios é compreender a dimensão cultural do conhecimento e considerar o currículo como produção cultural que precisa ser constantemente pensado, criticado e ressignificado, tendo em vista o contexto social, a diversidade de sujeito, o contexto da escola e a necessidade do conhecimento demandado.

Nos dias atuais, as reflexões sobre currículo, dentre outras questões, implicam pensarmos no lugar que a cultura e o conhecimento ocupam no espaço curricular, ou seja, nos conteúdos culturais que devem ser contemplados no currículo, de forma a não apenas garantir aos sujeitos aprendizes do direito a acessar conhecimentos e culturas diversas, como também de expressar a sua cultura e se perceber um sujeito sociocultural. Isto implica superar o pensamento curricular que contempla a cultura apenas como mais um conteúdo de ensino, o que pode cercear a memória e a identidade dos sujeitos que a fazem.

Portanto, partindo do pressuposto da indissociabilidade entre conhecimento e cultura, objetivamos, neste artigo, refletir sobre as relações entre currículo, cultura e conhecimento, para compreender os lugares que o conhecimento e a cultura têm ocupado nas discussões sobre currículo. Fundamos nossas reflexões no campo dos estudos curriculares e culturais. Para compreensão das teorias e concepções curriculares, utilizamos Silva $(2010,2020)$ e Candau (2013). Quanto às reflexões acerca do papel da cultura e do conhecimento, dentro do currículo, recorremos a Freire (2013), Lopes e Macedo (2011), Moreira e Candau (2007), Santomé (1998), Forquin (1993).

A questão dos conhecimentos e dos conteúdos presentes na seleção curricular, com vistas a uma educação de resultados satisfatórios para o indivíduo e para a sociedade, é uma das discussões postas 
na origem do campo de estudo das teorias curriculares, desenvolvidas a partir do século XX. As reflexões acerca dos currículos se estenderam a elaboração de novas conceituações, definições e significações, influenciadas pelos estudos culturais, na perspectiva do desenvolvimento sociocultural, subjetivo e identitário de um povo.

Para compreendermos o processo de ampliação das reflexões no campo de estudo curricular, discutiremos sobre as teorias curriculares, pontuando o contexto em que as discussões sobre a relação currículo e cultura emergiram nesse campo de estudo para, em seguida, refletirmos sobre o lugar que a cultura ocupa no currículo.

\section{CURRÍCULO E CULTURA: INTERLOCUÇÕES TEÓRICAS}

As diferentes teorias sobre currículo tecem olhares diversos sobre os conteúdos, os métodos, as relações de educação, cultura, poder e identidade, dependendo do contexto histórico em que foram elaboradas.

Segundo Silva (2020), a crítica ao modelo de ensino vigente no final do século XIX, baseado no ensino tradicional jesuítico, provocou novos desenhos e reflexões sobre educação, ensino e, consequentemente, ao currículo. O movimento por novos contextos educacionais fez emergir, no início do século XX, o termo currículo como indício de um campo especializado de estudo. Na época, os Estados Unidos apresentavam um contexto de estabelecimento da estatização e universalização da educação, valorizando-a como um objeto de estudo científico. Havia também uma preocupação com a formação de uma identidade nacional diante do crescimento industrial e urbano. Inicia-se, então, os estudos do campo curricular, com a preocupação em decidir sobre o que ensinar e a utilidade do que seria ensinado.

Foi no contexto do processo de industrialização americana que surgiu a teoria curricular tradicional ancorada nas ideias de Bobbitt (1918) e Tyler (1949). Com base na Teoria Comportamental Behaviorista e na teoria da administração Taylorista, esses teóricos construíram uma concepção de currículo cientificista e disciplinar, associado à administração escolar, colocando em prática conceitos como: eficiência, eficácia e economia, na organização curricular. A função do currículo na perspectiva tradicional de Bobbitt (1918), conforme Lopes e Macedo (2011, p. 22), "[...] é preparar o aluno para a vida adulta economicamente ativa a partir de dois conjuntos de atividades que devem ser igualmente consideradas pela escola - o que chama currículo direto e as experiências indiretas".

O currículo seria formulado a partir das grandes áreas encontradas na sociedade, subdivididas em atividades relacionadas aos objetivos do curso. Colocam, portanto, a centralidade do currículo nos objetivos, que devem ser claramente definidos e estabelecidos para se encaixar nas disciplinas já existentes, a elaboração do currículo seria uma atividade técnica voltada a organização e desenvolvimento, com pouca atenção à seleção dos conteúdos. Uma atividade mais burocrática que científica. Silva (2020) argumenta que as teorias curriculares tradicionais buscavam responder, através do seu modelo educacional, as perguntas: o que e como ensinar, a partir de um currículo conservador e unificado que equiparava o funcionamento da escola ao de empresas comerciais e industriais.

A teoria curricular tradicional, pelo caráter das transformações socioeconômicas daquele momento histórico, planeja as ações pedagógicas muito direcionadas aos interesses do mercado de trabalho e, consequentemente, desenvolve um currículo marcado pela cultura e valores das elites detentoras 
deste sistema de empregabilidade. Silva (Idem) salienta que mesmo diante desse contexto, em oposição aos currículos técnicos proposto por Bobbitt (1918) e Tyler (1949), o progressista John Dewey (1959) questiona essas ideias eficientistas, propondo um currículo progressista, preocupado com a democracia, oferecendo uma educação para a vida social harmoniosa e não apenas como preparação para a vida ocupacional.

A teoria curricular tradicional, portanto, concebe o conhecimento numa perspectiva instrumental, com fim determinado, que na concepção bobbittniana seria formar sujeitos eficientes e com habilidades necessárias ao desenvolvimento da produtividade social e econômica. Na atualidade, observa-se a presença deste pensamento nos currículos que priorizam os conhecimentos relacionados à formação de habilidades e competências, cujo fim é a formação para o mercado de trabalho.

Os estudos curriculares foram ampliados à medida em que as teorias curriculares tradicionais passaram a ser questionadas pelas chamadas teorias curriculares críticas. As teorias críticas surgiram entre os anos de 1960 e 1970, período em que o mundo passava por diversos movimentos pelos direitos sociais e culturais, cujo contexto favoreceu o desenvolvimento de novos estudos no campo educacional (SILVA, 2020). Dentre os estudos que questionam os modelos dos currículos tradicionais, encontram-se o movimento da reconceptualização, nos Estados Unidos, a nova sociologia da educação, na Inglaterra, a obra de Paulo Freire, no Brasil, e os estudos de sociólogos franceses.

O referido autor destaca que o campo de estudos curriculares críticos se ancorou em duas vertentes teóricas: a marxista e a fenomenológica. Na visão crítica marxista, a escola atua ideologicamente através do currículo, estabelecendo uma relação entre escola e economia, entre educação e produção. A escola reproduz a sociedade capitalista em suas desigualdades sociais, transmitindo, por meio das matérias escolares, conhecimentos, valores e atitudes como sendo bons e desejáveis, tanto para as classes dominantes quanto para as dominadas. Refletindo a questão, os sociólogos franceses Bourdieu e Passeron, estendem o conceito reprodutivista para o que denominaram de reprodução cultural. Para estes sociólogos, é através da reprodução da cultura dominante que a reprodução mais ampla da sociedade fica garantida. Assim os valores, costumes e comportamentos da cultura dominante passam a ter valor social, constituindo-se em capital cultural (SILVA, 2020).

De acordo com os reprodutivistas, na escola, a reprodução é ocultada através do currículo, que é constituído em sua expressão e transmissão a partir da cultura dominante. Isso faz com que os estudantes das classes dominantes vejam a sua cultura vivenciada e valorizada, enquanto os estudantes das classes populares, além de terem dificuldades para compreender o capital cultural desconhecido, veem a sua cultura originária desvalorizada. Silva (2020) acrescenta que, preocupados com a reprodução social e cultural produzidas através das relações estruturais, Bowles e Gintis (s/d), utilizam o conceito de currículo oculto para designar, para além do currículo explícito, os elementos do ambiente escolar em que se ensina atitudes, comportamentos e valores, que reforçam as pautas injustas de dominação social ligadas a nacionalidade, gênero, sexualidade, raça, etnia.

Outra visão surgida das teorizações críticas marxistas, pontuada pelo autor, parte das análises feitas por Henry Giroux (1981), que aplicando teorizações sociais mais amplas, foca seus estudos na dinâmica cultural. Utilizando o conceito de resistência, propõe que docentes e discentes promovam a construção de um currículo político, crítico dos arranjos dominantes. Dessa forma, o currículo seria capaz de construir um processo pedagógico no qual as pessoas teriam consciência do controle exercido pelas estruturas sociais. Para o teórico, o currículo traria a construção de significados e 
valores culturais, não apenas subjetivamente, mas ligados às relações sociais de poder, uma vez que a política cultural permeia o campo da pedagogia e do currículo.

Em referência a vertente fenomenológica, Lopes e Macedo (2011) destacam o movimento da reconceptualização do currículo. Para os reconceptualistas, a estrutura curricular composta por objetivos, metodologia e avaliação não faz relação significativa com o mundo real das experiências subjetivas. A ênfase da crítica fenomenológica está nos significados subjetivos que as pessoas dão às suas experiências pedagógicas e curriculares. Dessa forma, concebem o currículo como um local em que discentes e docentes vão problematizar os significados das suas experiências, conectando-as à estrutura econômica da sociedade. As experiências e os questionamentos dos estudantes seriam utilizados como objetos de investigação e o currículo seria proposto através da seleção de temas de interesse, relacionados ao mundo vivido, rompendo completamente com o modelo de currículo tradicional e a ordem social estabelecida.

As teorias curriculares críticas historicamente têm denunciado o caráter ideológico presente na organização curricular dos conhecimentos, que tradicionalmente estaria a serviço da cultura de dominação. Fazem, portanto, uma crítica centrada na maneira estrutural em que está posto o processo educacional, refletindo sobre as relações de educação, poder e identidade. "As teorias críticas do currículo efetuam uma completa inversão nos fundamentos das teorias tradicionais" (SILVA,2020, p. 29), ao questionar pela primeira vez o tipo de modelo educacional utilizado.

Consequentemente, as teorias críticas colocam em questão os arranjos sociais e educacionais aplicados ao currículo, "desconfiam do status-quo" e, em algumas análises, como as citadas anteriormente, vislumbram um olhar para além do estruturalismo econômico, refletem sobre os valores de respeito e tolerância às diversidades socioculturais, trazem problematizações sobre a função social do currículo e suas implicações na formação dos sujeitos. Sob a luz das teorias críticas do currículo, o conhecimento escolar foi problematizado e a suposta neutralidade foi questionada. Os teóricos críticos não estavam preocupados em discutir que conhecimento selecionar, mas porque determinados conhecimentos são selecionados em detrimentos de outros.

Foi no bojo das teorias críticas do currículo que emergiram as questões sobre a relação entre cultura e currículo, desvelando o caráter reprodutivista e ideológico, ligados às relações sociais de poder presentes no currículo tradicional. A ampliação das teorias críticas, em meados do século XX, para além das questões estruturais, traz ao centro dos estudos curriculares o desdobramento das questões relacionadas à cultura e ao currículo, a partir da perspectiva multiculturalista. Surgem as teorias póscríticas, compostas por concepções pós-modernistas, pós-estruturalistas e pós-colonialistas, produzindo inferências acerca da compreensão das bases sociais e epistemológicas do currículo, refletindo não apenas as determinações de estruturas sociais, mas também determinações como gênero, raça e sexualidade (SILVA 2020).

O autor ainda coloca que a concepção pós-estruturalista contribui para a análise multicultural ao considerar que as diferenças culturais ocorrem essencialmente por meios de processos linguísticos de significações. Desse modo, as diferenças culturais vão sendo normatizadas por meio dos discursos e significados construídos socialmente. O discurso que promove a diferença se dá em articulação com as relações de poder presentes entre os grupos. Sendo assim, é preciso questionar o processo pelo qual algo foi considerado verdade, porque esse algo se tornou verdadeiro e chegou a fazer parte da seleção curricular. Sob essa perspectiva, poderá haver uma reflexão de desconstrução dos binarismos e das rígidas separações presentes nos conhecimentos que compõem o currículo atual. 
O pós-modernismo vem em oposição às metanarrativas baseadas na razão, na racionalidade e no progresso, do mundo moderno. Na percepção de Silva (2020, p. 113), "o pós-modernismo reserva um dos seus mais fulminantes ataques ao sujeito racional, livre, autônomo, centrado e soberano da Modernidade". Em sua vertente estética, o pós-modernismo se apresenta ambíguo, privilegiando a mestiçagem e o hibridismo entre as culturas e modos de vida, preferindo o local ao universal. Os curriculistas pós-modernos ressaltam a incompatibilidade entre o currículo existente, que é linear, sequencial, disciplinar e baseado em binarismos (alta e baixa cultura, conhecimento científico e cotidiano) e o mundo pós-moderno, no qual todos estão conectados. É, portanto, um questionamento das teorizações curriculares e de educação críticas, que dependem do universalismo, essencialismo e fundacionismo do pensamento moderno e que prevalecem nos marcos legais das políticas educacionais.

Seguindo a busca pela compreensão do mundo contemporâneo e globalizado, as teorias póscolonialistas vão refletir, a partir da expansão imperial europeia (séc. XV), as relações de poder entre as metrópoles, que começam a partir das relações de dominação e colonização, "[...] para incluir as relações atuais de dominação entre as nações, baseadas na exploração econômica e no imperialismo cultural [...]" (SILVA, 2020, p. 125). Diante deste pressuposto, o autor esclarece que a teoria póscolonial se preocupa com a análise das obras literárias escritas por pessoas das nações dominantes e nações dominadas. O primeiro grupo produz obras com narrativas de submissão dos povos colonizados, enquanto o segundo produz obras literárias com narrativas de resistência ao poder imposto. Ao analisar as expressões literárias e artísticas dos povos colonizados, o pós-colonialismo faz uma crítica aos currículos centrados nas obras literárias e artísticas ocidentais, pleiteando a inclusão das formas culturais subjugadas pela identidade europeia dominante.

Os Estudos Culturais, iniciados a partir de 1964, na Universidade de Birmingham, Inglaterra, com a criação do Centro de Estudos Culturais Contemporâneos, trazem importantes contribuições para discussões sobre a relação currículo e cultura. Em referência, Silva (2020) pontua que o conceito de cultura criado pelos teóricos do campo dos estudos culturais contesta a perspectiva economicista, concebendo a cultura como um campo de luta, significação social e de identidade dos diferentes grupos que compõem as sociedades. A cultura é um jogo de poder em que as produções culturais dos vários grupos sociais reivindicam por significação social. Sendo assim, os estudos culturais, ao analisar a cultura, levam em consideração as relações de poder, significação e identidade.

Expandindo essa compreensão para o campo do conhecimento e do currículo, estes passam a ser vistos também como um campo cultural, no qual ocorre disputa em torno de significação e de identidade. Neste sentido, a relação currículo e cultura, como prática de significação no contexto das relações sociais, possibilita a construção de identidades sociais e culturais dos indivíduos e dos grupos, através da valorização dos conhecimentos produzidos pelos mais diversos grupos. Sob a perspectiva cultural, os conhecimentos presentes no currículo são tidos como resultado de um processo de construção, de criação e de interpretação social. Em vista disso, não se encontra sentido na rígida separação entre ciências naturais e sociais ou entre conhecimento escolar e conhecimento cotidiano, já que ambos são objetos culturais e possuem a natureza de construção e de interpretação do conhecimento.

Os estudos culturais trazem ao terreno das teorizações curriculares a possibilidade de validação de novos saberes, pois diminuem a separação entre conhecimento acadêmico e escolar e conhecimento cotidiano e cultural. Essa aproximação é possível a partir da perspectiva de que todo conhecimento 
produzido dentro de um sistema de significação deve ser visto como cultural, tal constatação é obtida através da análise das diversas formas culturais presentes nas instâncias sociais. Abordando as formas culturais como processo cultural significativo, é possível perceber que todas contribuem para a criação e a transformação de identidades e subjetividades e é a partir dessa constatação que os estudos culturais promovem uma equivalência entre as diferentes culturas. Dessa forma, o cultural tem o seu lado pedagógico e a pedagogia tem a sua forma cultural, cabendo a comparação entre os processos escolares e os processos de sistemas culturais extraescolares (SILVA, 2020).

\section{CONHECIMENTO E CULTURA: QUE LUGAR OCUPAM NO CURRÍCULO?}

Na busca das relações entre cultura, currículo e conhecimento, encontramos autores como Forquin (1993, p.14), que considera a cultura como "[...] o conteúdo substancial da educação, sua fonte e sua justificação última: a educação não é nada fora da cultura e sem ela". A educação não terá sentido nem condições de existir fora da cultura, uma vez que é função do trabalho docente a transmissão e perenização da cultura. Segundo o autor, o fazer pedagógico não pode fugir ao trabalho material da cultura, pois estabelece as relações com o passado e o presente e, assim, mantém a cultura viva e atualizada. Nesse nível mais geral, educação e cultura aparecem como duas faces recíprocas de uma mesma realidade, na qual uma não pode ser pensada sem a outra, entretanto, cabe considerar e refletir sobre qual cultura o currículo está contemplando e o porquê de tais conhecimentos serem considerados como conhecimento cultural.

Analisando crítica e historicamente as propostas curriculares, Santomé (1998) alerta para a presença abusiva das culturas hegemônicas em detrimento das culturas minoritárias que não possuem estruturas de poder. Segundo o autor, culturas infantis e juvenis; etnias minoritárias ou sem poder; o mundo feminino; as sexualidades lésbica e homossexual; a classe trabalhadora e o mundo das pessoas pobres; o mundo rural e ribeirinho são exemplos de culturas minoritárias que foram, ao longo do tempo, contempladas apenas como conteúdos curriculares complementares. Esse fato pode ser observado no livro didático, que sempre foi alvo de críticas dos educadores mais progressistas, por contemplar de forma equivocada e fragmentada a historicidade de determinadas culturas, colocandoas numa posição de inferioridade, submissão e marginalização.

Na realidade brasileira, a cultura teve espaço na educação como prática discursiva e emancipatória a partir das teorizações e práticas de Paulo Freire com a cultura popular. Para Lopes e Macedo (2011, p. 85), o trabalho de Paulo Freire instituiu à educação um maior entendimento em torno da "[...] produção de significados do currículo. Com isso também abre espaço para uma linguagem da possibilidade, para além da lógica da reprodução". Tendo por base a pedagogia crítica e uma educação popular voltada aos trabalhadores rurais, Freire busca contribuir com a luta dos oprimidos por meio do diálogo de conscientização política e libertária. O educador pauta a ação pedagógica na realidade, construindo com os seus educandos a transformação dela. Assim, a educação se faz com o outro, não é algo de domínio apenas do educador, nem tão pouco de domínio de um conteúdo programático externo às realidades. Não se trata de um conteúdo programático a ser depositado, mas sim dialogado, buscando-se "[...] conhecer, não só a objetividade em que estão, mas a consciência que tenham desta objetividade; os vários níveis de percepção de si mesmos e do mundo em que e com que estão" (FREIRE, 2013, p.49).

Para Moreira e Candau (2007, p. 22), o currículo "constitui um dispositivo em que se concentram as relações entre a sociedade e escola; entre os saberes e as práticas socialmente construídas e os 
conhecimentos escolares". Partindo dessa compreensão, os autores concebem o conhecimento escolar como uma etapa específica da esfera educativa. É um tipo de conhecimento produzido pelo sistema escolar e pelo sistema social e econômico mais amplo, em que essa produção se dá em meio às relações de poder entre ambos. O currículo precisa, portanto, ser refletido criticamente pelos educadores, a partir dos conhecimentos e dos discursos pedagógicos assumidos em seu processo de elaboração.

Conforme Forquin (1993), a escola necessariamente faz uma seleção de conteúdos culturais e posteriormente uma reelaboração didática desses conteúdos, para tornar possível a realização do trabalho docente. Para Lopes e Macedo (2011), o conhecimento presente no currículo escolar passa por uma transposição didática, para então virar o corpo do conhecimento curricular, que será tratado na relação didática entre professor e aluno. As autoras, citando Chervallard (s/d), explicam o processo de transposição didática de um conceito matemático:

O conceito é deslocado: (i) das questões que permitem resolver e dos conceitos com os quais constitui uma rede de relações (descontextualização); (ii) do período histórico (descontemporização); (iii) dos vínculos que possui com as pessoas que o produziram e suas práticas científicas (despersonalização). Simultaneamente, o conceito é naturalizado, como se sua produção respondesse a verdades incontestáveis (LOPES; MACEDO, 2011, p. 96).

O exemplo demonstra as mudanças conceituais que podem ocorrer na transposição dos conhecimentos científicos para os conhecimentos didáticos. Compreendemos também que o conhecimento escolar tem como referência, além do saber científico, os saberes das práticas socioculturais universais, pois o conhecimento a ser ensinado e aprendido na escola tem relação com um conhecimento utilizado socialmente para um determinado fim. É importante aos educadores conservarem um olhar atento em relação ao porquê de determinados conhecimentos socioculturais se fazem historicamente presentes nos currículos escolares, enquanto outros estão ausentes ou minimizados. É necessário atenção para a ocorrência de um conhecimento pronto, no qual não cabem inferências, isso certamente não será o desejável.

Ao passar pela transposição didática, os saberes sofrem a incorporação de determinados valores sociais. Preocupado com a linguagem presente nos instrumentos pedagógicos, Bernstein (1996), citado por Lopes e Macedo (2011), cria o conceito da recontextualização. A recontextualização é uma espécie de controle do discurso pedagógico, no qual esse discurso é produzido a partir da ordem discursiva dominante, fora do contexto pedagógico. Com isso, o discurso pedagógico não tendo sentido próprio, passa a ser usado como princípio recontextualizador, colocando os discursos originais em bases sociais que favorecem relações de controle e poder. Segundo as autoras, o discurso pedagógico combina com o discurso institucional (DI) e o discurso regulatório (DR), sendo o primeiro técnico, relacionado a competências especializadas e conceitos, e o segundo moral, criando ordem, relações e identidades.

Além dos processos de descontextualização e recontextualização dos conhecimentos, o currículo também sofre influências dos estudos sobre desenvolvimento humano. Isso pode ocorrer quando a seleção e a organização dos conhecimentos escolares são propostas a partir das sequências e dos ritmos da Psicologia do desenvolvimento (MOREIRA; CANDAU, 2007). As unidades escolares e os professores podem elaborar atividades didáticas com conteúdo adequados à etapa de desenvolvimento, a qual eles acreditam que os estudantes estão. Com isso, podem produzir um 
ensino reduzido em possibilidades e até subestimar "o quanto muitos(as) de nossos(as) estudantes conseguem 'queimar etapas' e aprender" (MOREIRA; CANDAU, 2007, p. 24. Grifo dos autores).

Uma proposta neste sentido pode ser encontrada na literatura de César Coll, no livro Psicologia e Currículo, de 1987. Segundo Lopes e Macedo (2011), neste livro, o autor relata sua experiência na reforma curricular espanhola, baseada em teóricos da Psicologia do desenvolvimento, articulando conhecimentos da Psicologia genética, Zona de Desenvolvimento Proximal, de Vygotsky, conhecimentos prévios e atividades significativas de Ausubel, e a perspectiva construtivista de Piaget. As autoras acrescentam que na proposta os conteúdos são considerados como saberes e formas culturais e são definidos visando a aquisição dos objetivos gerais da área. É uma proposta de currículo hierarquizada, de conteúdo taxinomizados e determinados pelos sistemas legais, com objetivos definidos de forma comportamental e com vistas à avaliação. Dessa forma, acaba articulando as perspectivas construtivistas da aprendizagem, que favorecem o trabalho com as identidades e a cultura, com a centralização das decisões curriculares, promovendo, assim, um sentido dual.

Outro aspecto dos processos de construção do conhecimento escolar é que ele é submetido aos meios pedagógicos que permitem a sua avaliação. Ensina-se os conhecimentos que possam ser mais facilmente avaliados (MOREIRA; CANDAU, 2007). Esse procedimento favorece a questão da hierarquização das disciplinas no currículo linear. O currículo privilegia as disciplinas do campo das ciências exatas, com maior carga horária e mais cuidado na avaliação, ficando as disciplinas ligadas às ciências humanas, que carregam a cultura na historicidade dos povos, das artes, dos movimentos religiosos, relegadas a um patamar inferior e de menor importância. Para Santomé (1998), essas modalidades curriculares levam os estudantes e o próprio corpo docente a compreender que a matemática, por exemplo, é mais valiosa que as ciências sociais ou as artes. "O conhecimento aparece como um fim a-histórico, como algo dotado de autonomia e vida própria, à margem das pessoas" (SANTOMÉ, 1998, p. 107).

Esse processo hierarquizado de valorização de algumas disciplinas revela que a construção do conhecimento curricular sofre forte efeito nas relações de poder. Desta forma, acreditar na ideia de neutralidade entre conhecimento, cultura, currículo e educação, pode ser um pensamento ingênuo, frente a complexidade de elementos que se apresentam como fatores determinantes do processo de seleção e de reelaboração dos conteúdos curriculares.

\section{CONSIDERAÇÕES FINAIS}

A discussão sobre o que deve ser contemplado como conhecimento no campo do currículo escolar varia entre o assentimento dos vários saberes existentes como conhecimentos válidos e o universalismo, que tende a considerar alguns saberes como os mais adequados e verdadeiros. Para fazer essa consideração do saber verdadeiro, o currículo é pensado e planejado a partir de diferentes valores e critérios e cada um desses critérios recebe suas críticas, a saber: critérios econômicos, acadêmicos, científicos e disciplinares ligados ao atendimento das necessidades do mercado de trabalho; critérios ideológicos, relacionados à reprodução cultural de dominação das massas; critérios pertencentes à Psicologia do desenvolvimento, baseado nos caracteres genéticos e cognitivos; critérios pautados na avaliação pedagógica que reforçam a organização linear de disciplinas privilegiadas; critérios culturais, que buscam constituir o currículo na própria crítica cultural, valorizando a produção do conhecimento nos diversos grupos sociais por meio da significação. 
Em todos esses critérios, fora observada uma intensa relação de poder. Buscando por significado e identidade, cada grupo social quer ter legitimado e reconhecido seus valores socioculturais. Nessa intensa disputa entre os defensores dos vários critérios, acaba prevalecendo a força das classes detentoras de poder político, econômico e de comunicação de massas, pois estas têm nas mãos as ferramentas para viabilizar a disseminação dos seus valores e da sua cultura, para institucionalizá-la como "legítima". O debate, a nosso ver, não cessa devido a impossibilidade de um consenso final, mediante a natureza complexa das temáticas de discursos ligadas ao currículo, que abrange desde a estrutura social, econômica, ideológica, até as relações de cultura, liberdades, identidades e tantas outras. Percebemos que não é possível discutir o currículo apenas a partir dos conhecimentos, uma vez que todo conhecimento provém da produção de algum grupo social e possui significação para este.

Em face da complexidade do currículo, algo se apresenta com regularidade, mediante algumas das análises envolvidas. Chama atenção o fato de haver sempre posições opostas entre os sujeitos: os que dominam os conhecimentos "legítimos" e os que dominam os conhecimentos "ilegítimos"; os que selecionam os conhecimentos do currículo e os que são submetidos a esta seleção; os que veem a sua cultura praticada e valorizada e os que são submetidos a processos de inferiorização cultural. Essas interpretações opostas podem tornar mais difícil a compreensão e a construção de um currículo que contemple sem categorizações as questões sociais e os saberes culturais. É preciso considerar o hibridismo entre conhecimentos e culturas e os contextos sociais que produzem significados e os legitimam, para melhor superar as desigualdades. Posto isto, refletimos que a cultura perpassa por todas as linearidades que o currículo possa apresentar, como por exemplo: base comum, parte diversificada e a prática cotidiana em sala de aula.

Diante das reflexões apresentadas, podemos inferir que não há possibilidade da educação escolar existir fora dos processos culturais presentes nos contextos em que é vivenciada. É necessário à educação um currículo pensado a partir da realidade das multiculturas do mundo contemporâneo, que seja capaz de propiciar espaços e tempos de ensino-aprendizagem significativos aos contextos socioculturais existentes. Assim, o currículo pode ter por base uma perspectiva multicultural propositiva, conforme enuncia Candau (2013, p. 20), ao dizer que "a perspectiva propositiva entende o multiculturalismo não simplesmente como um dado da realidade, mas como uma maneira de atuar, de intervir, de transformar a dinâmica social". Um projeto político-cultural, capaz de propiciar uma intervenção e transformação social a partir do trabalho com as relações culturais da sociedade.

Nas condições atuais em que se encontra a educação brasileira, faz-se cada vez mais urgente e desafiante discutir e colocar em curso um projeto educativo que tenha como base a relação conhecimento e cultura, tendo em vista o retrocesso conceitual que as recentes reformas impuseram à prática curricular, alicerçada em competências e habilidades. Tais reformas, principalmente as direcionadas ao ensino médio, revisita a concepção de currículo instrumental, "em nome de um 'direito de aprendizagem' (BNCC) que não dialoga com a realidade dos sujeitos e inibe o potencial transformador do currículo", conforme alerta Ponce e Zanardi (2021, p. 3. Grifo dos autores).

Compreendemos que o currículo está no centro de muitas disputas: formação de identidades culturais, de gênero, questões raciais e de sexualidade; espaço de significação; processos de representação, inclusão e exclusão; produção de conhecimento e saber. Portanto, não é mais possível o conceber como um mero instrumento burocrático de transmissão de conhecimentos, nem tampouco atrelar a sua utilização a um projeto social centrado nos valores puramente econômicos com significados na 
globalização, flexibilização e competitividade. É preciso considerar os questionamentos em disputa para uma nova concepção social dos sujeitos, do currículo, da cultura e do conhecimento. Uma concepção que construa um espaço de ação, no qual haja a possibilidade de decidir hoje, por uma significação que não esteja previamente determinada.

\section{REFERÊNCIAS}

CANDAU, Vera Maria. Multiculturalismo e educação: desafios para a prática pedagógica. In: MOREIRA, Antônio Flávio Barbosa; CANDAU, Vera Maria. Multiculturalismo: diferenças culturais e práticas pedagógicas. Petrópolis: Vozes, 2013.

FARIA, Ernesto. O que os dados do IDEB de 2019 dizem sobre a aprendizagem dos alunos. Nova Escola. 2020. Disponível em: https://novaescola.org.br/conteudo/19892/o-que-os-dados-do-ideb2019-dizem-sobre-a-aprendizagem-dos-alunos. Acesso em mar. 2021.

FORQUIN, Jean Claude. Escola e cultura: as bases sociais e epistemológicas do conhecimento escolar. Trad. Guacira Lopes Louro, Porto Alegre: Artes Médicas, 1993. 205p.

FREIRE, Paulo. Pedagogia do oprimido, 67a. ed. Rio de Janeiro: Paz e Terra, 2013.

LOPES, Alice C.; MACEDO, Elizabeth. Teorias do Currículo $1^{\text {a }}$ ed. São Paulo. Cortez, 2011. 280p.

MOREIRA, Antônio Flávio Barbosa; CANDAU, Vera Maria. Indagações sobre o currículo: Currículo, Conhecimento e Cultura. Ministério da Educação, Secretaria de Educação Básica: Brasília, 2007, p. $17-48$

PONCE, Branca Jurema; ZANARDI, Teodoro A. Costa. Apresentação do Dossiê Temático: de que currículo precisamos em tempos de democracia fraturada, subtração de direitos sociais e crise sanitária de profunda gravidade?" Revista e-Curriculum, São Paulo, v.19, n.4, p. 1403-1405, out./dez. 2021. Disponível em: http://revistas.pucsp.br/index.php/curriculum. Acesso em: 15 de fev. 2022.

SANTOMÉ, J. T. Globalização e Interdisciplinaridade: o currículo integrado. Porto Alegre: Artes Médicas Sul Ltda., 1998.

SILVA, Tomaz Tadeu da. Currículo como fetiche: a poética e a política do texto curricular. 1. ed., 4 reimp. Belo Horizonte: Autêntica, 2010.

SILVA, Tomaz Tadeu da. Documentos de Identidade: Uma Introdução às Teorias de Currículo.3. ed. ;12 reimp. Belo Horizonte: Autêntica, 2020.

Submissão: 10/11/2021

Aceito: 24/02/2022 